\title{
Economics
}

The Open-Access, Open-Assessment E-Journal

Vol. 12, 2018-55 | August 21, 2018 | http://dx.doi.org/10.5018/economics-ejournal.ja.2018-55

\section{Social status, preferences for redistribution and optimal taxation: a survey}

\section{Andrea Gallice}

\begin{abstract}
The author reviews recent studies that investigate how social status concerns influence individual preferences for redistribution and impact the design of optimal tax policies. He focuses on two aspects: the relevant dimension over which relative concerns are defined and the different formalizations of the notion of social status that the authors provide.

(Published in Special Issue The economics of social status)
\end{abstract}

JEL D31 D62 H21 H23

Keywords Social status; redistribution; externalities; optimal taxation

\section{Authors}

Andrea Gallice, University of Torino, Italy; Collegio Carlo Alberto, Torino, Italy, andrea.gallice@carloalberto.org

Citation Andrea Gallice (2018). Social status, preferences for redistribution and optimal taxation: a survey. Economics: The Open-Access, Open-Assessment E-Journal, 12 (2018-55): 1-17. http://dx.doi.org/10.5018/economics-ejournal.ja.2018-55 


\section{Introduction}

There is ample evidence that positional concerns and status competition influence people's preferences and behavior (Chao and Schor, 1998; Solnick and Hemenway, 1998, 2005; Luttmer, 2005; Heffetz and Frank, 2011), and theoretical models that take this into account have proven to lead to more sensible results, not only at the individual level but also in terms of welfare and policy implications (Postlewaite, 1998; Rege, 2008; Truyts, 2010).

In this brief survey, I review a number of papers that investigate the economic consequences of agents' concerns for social status in two specific and closely related areas of research. The first area pertains to how status concerns influence individual preferences for redistribution (hence, taxation). The second area focuses on how optimal direct taxation should be designed when agents care about their relative standing in the society.

Studies that have addressed the first research question have mainly pursued a positive analysis: backed by empirical evidence that stems from international surveys, they argue that status concerns may explain voting behaviors that appear detrimental to individual well-being if one only considers monetary payoffs. Papers that fall into the second area of research instead adopt more of a normative approach as they investigate the features of the optimal tax schedule when status competition generates externalities and leads to inefficiencies.

I focus in particular on 12 recent papers that I perceive to be important in the recent literature on the two topics of interest. This small sample of papers is well balanced: six investigate the impact of social concerns on redistributive preferences and six study the issue of optimal direct taxation when people care about their relative standing in the society. All of the papers that I discuss were published in 2000 or later, and six of them were published in 2012 or later. In presenting and discussing these contributions, I attempt to highlight the following two aspects of the analysis: 1) what is the relevant dimension of status competition that the authors consider (i.e., what is the status-bearing object), and 2) which functional form the authors use to capture the notion of social status.

\section{Social Status and Preferences for Redistribution}

The line of research that studies how social status concerns can shape individual preferences for redistribution fits into the broader research agenda that aims to identify all of the determinants of these preferences.

In this respect, standard models of political economy (see the seminal papers by Romer (1975), Roberts (1977), and Meltzer and Richard (1981)) advanced the notion of economic voting (or pocketbook voting), which, in its basic formulation, identifies income as the sole driver of individuals' attitudes towards redistribution. According to these models, low-income individuals should favor redistribution ("poor" agents gain from the redistributive scheme because what they pay is less than what they get back), and high-income individuals should oppose redistribution ("rich" agents pay more than what they get). From an empirical point of view, the negative relation between income and support for redistributive policies has been studied extensively (see, for instance, Fong (2001)). International surveys such as the World Value Survey, the European Social 
Survey, and the General Social Survey routinely collect information about respondents' income and their attitudes towards redistribution. These data make it possible to study how the two variables relate, while also controlling for a number of relevant covariates (e.g., age, education, political preferences). The data show that economic voting indeed describes the behavior of a large portion of the population. However, the data also exhibit two systematic deviations from this paradigm. Many members of the working class appear to be against redistribution; at the same time a sizable fraction of the socioeconomic elite declare their support for relatively high levels of redistribution.

The magnitude and the robustness of these deviations, paired with the pronounced cross-country heterogeneity that these surveys highlight, motivated the search for other factors in addition to income that may possibly influence individual preferences for redistribution. ${ }^{1}$ These factors include prospects of social mobility ((Piketty, 1995; Bénabou and Ok, 2001), beliefs concerning returns on effort (Bénabou and Tirole, 2006), perception about the fairness of market outcomes (Alesina and Angeletos, 2005), and a number of agents' idiosyncratic characteristics such as their personal histories (Giuliano and Spilimbergo, 2014), race (Alesina and Ferrara, 2005), and culture (Luttmer and Singhal, 2011).

A number of studies have argued that social status concerns may also play a role in influencing voters' attitudes towards redistribution. There are many channels through which this effect can flow. Clearly, redistribution modifies an agent's disposable income and therefore his consumption possibilities. As such, redistribution also affects the resources that the agent can devote to conspicuous consumption, which is the standard way in which individuals signal their status. Moreover, redistribution makes the society more equal and accordingly shrinks the distribution of consumption. As such, it decreases the social prestige (social stigma) that high-income (lowincome) individuals experience when status is defined as a cardinal concept. ${ }^{2}$ Redistribution can also affect ordinal status if it impacts individuals' incomes in an inhomogeneous way and thus modifies agents' relative standing in the distribution. Finally, redistribution can also change the relevance that the society attributes to different individual characteristics in determining status. It can therefore benefit or harm voters based on their initial endowment of these characteristics.

In what follows, I explore and discuss these possibilities in more detail. Most of the papers that I review in this section are theoretical. I start, however, with a discussion of an empirical paper (Corneo and Grüner, 2002) that testifies that social status concerns do indeed influence agents' preferences for redistribution.

Corneo and Grüner (2002) use survey data from the International Social Survey Programme to evaluate the explanatory power of three competing forces in driving agents' support for redistributive policies. The three forces that these authors consider are: 1) The monetary consequences that the redistributive scheme has on the individual (the authors call this force the "homo oeconomicus effect,' essentially economic voting), 2) How the scheme conforms with the agent's public values

\footnotetext{
1 See Alesina and Giuliano (2011) for a review.

2 Social status is ordinal when an agent's position in the society is fully determined by the rank that the agent occupies in the distribution of consumption / possession of the status-bearing object. Social status is cardinal when an agent's position in the society also depends on the distance between his own level of consumption / possession and some aggregate statistics of others' level (say, the average in the population). Bilancini and Boncinelli (2008, 2014) show that the two notions of social status are far from being equivalent and may actually lead to radically different model predictions.
} 
and vision about how the society should be (the 'public values effect'), and 3) How the policy affects the agent's relative consumption and living standard (the 'social rivalry effect'). This last force is clearly related to the notion of social status. The mechanism that the authors have in mind is the following: individuals have different incomes, but they tend to mingle with people with similar income (for instance by living in the same neighborhood). Society is therefore partitioned into different income classes, and classes with higher income enjoy higher social prestige. Redistribution shrinks the distribution of income and accordingly moves adjacent income classes closer. As such, an individual of class $k$ now has more opportunities to meet and interact with individuals that belong to income classes $k-1$ (i.e., a bit poorer) and $k+1$ (i.e., a bit richer). The first effect decreases the expected utility that the agent derives from social interactions, and the second effect increases expected utility. If the total effect is negative, the agent should oppose redistribution; if it is positive he should support it. Empirical results (the authors use standardized measures of occupational prestige to define the social prestige that they attach to the various income classes) confirm the sign and the significance of this relation. The hypothesis that the desire to obtain high status shapes individual preferences for redistribution is therefore validated. ${ }^{3}$

Closely related to this study is another by the same authors: Corneo and Grüner (2000). Both studies highlight the relevance of status effects in influencing agents' redistributive preferences. However, while Corneo and Grüner (2002) is an empirical paper, Corneo and Grüner (2000) is mainly theoretical. Corneo and Grüner (2000) aim to rationalize a puzzling observation, namely the fact that the possibility to express one's own preferences about redistribution (i.e., the right to vote about taxes) is more prevalent in countries that feature pronounced income inequalities. Given that the income distribution is typically right-skewed (i.e., the median voter has an income below the mean), why then people do not vote for more redistribution? To answer this question, Corneo and Grüner (2000) propose a model in which economic inequality has an informational value that makes it possible to infer agents' unobservable characteristics (e.g., non-marketable skills such as culture and taste) via their observable characteristics (e.g., consumption). It is this informational value of inequality that limits the scope for redistribution; in a completely equal society all agents would have the same consumption level, making it impossible to tell different agents apart. The authors argue that it is this fear of losing their social status that keeps members of the middle class from supporting more redistributive policies and makes them agree with the elites to support more conservative taxation policies and therefore less redistribution. From a technical point of view, Corneo and Grüner (2000) study a three-period model in which agents first vote on their preferred level of redistribution, then consume their (post-redistribution) income, and finally voluntarily match into pairs. The matching process follows the model of Cole et al. (1992) and features social competition as the (unobservable) matching value of an individual is positively correlated with his (unobservable) wealth endowment or gross income, which are status-bearing objects and are in turn positively correlated with the agent's (partially observable) level of consumption. The latter therefore serves as a signal for status. ${ }^{4}$

\footnotetext{
3 For completeness, Corneo and Grüner (2002) find that also the two other forces, the 'homo oeconomicus effect' and the 'public values effect', have significant explanatory power.

4 Ferrari (2018) extends the model by Corneo and Grüner (2000) by letting individuals signal their (ordinal) status through the consumption of a conspicuous good. The game features different equilibrium profiles of conspicuous consumption, which thus lead to different possible stratifications of the society in terms of redistributive preferences.
} 
A similar matching protocol has been used more recently by Levy and Razin (2015). These authors study preferences for redistribution in a setting in which agents only interact with individuals who belong to the same "club" (i.e., a partition of the society with respect to income). Levy and Razin (2015) do not model status concerns explicitly. As such, they do not rely on any particular (ordinal or cardinal) notion of social status. In their model, agents positively sort according to their disposable income. This endogenously leads to social stratification, because agents spend resources to access more prestigious clubs. Relevant examples include investments in the education market (say, the choice of a pupil's school) and in the marriage market. The sorting mechanism in turn affects individuals' preferences for redistribution. The intuition is that, by decreasing income inequality, redistribution reduces the incentives to sort. In particular, Levy and Razin (2015) show that when the distribution of gross incomes is relatively equal, all individuals up to the mean, and most interestingly also some above, prefer full equality (i.e., maximum taxation) so to eliminate the pressures to engage in costly sorting. On the contrary, high inequality in the distribution of gross incomes may lead some individuals who are below the mean to oppose redistribution, because sorting gives them the option of not getting stuck in "poor" clubs. ${ }^{5}$ The model by Levy and Razin (2015) can therefore rationalize both deviations from pure economic voting (blue collar individuals voting against redistribution, members of the elite voting in favor of it), albeit not simultaneously and within the same society.

König et al. (2017) provide an alternative explanation as to why affluent individuals may support redistribution. These authors focus on a specific form of redistribution, namely the public provision of goods for which a market alternative also exists. Examples of this kind of redistribution include education, childcare and housing. The intuition here is that rich individuals may support public provision to maintain the private substitute elitist (though not necessarily of a better quality) and therefore signal their social prestige. In terms of the model, König et al. (2017) assume that citizens differ in their exogenous income, which is not directly observable, and they derive utility from general consumption as well as from consuming a good they can either receive for free from the government or decide to buy on the market. The two options entail different status consequences that are endogenously determined as a function of the partition of the society into public and private sector users. In particular, the status that an alternative generates is proportional to the average income of the agents who use it. Affluent individuals then strategically support public provision: the majority of less well-off agents will use the public alternative so that the private alternative will be only bought by high-income families and therefore entail high social prestige. An interesting feature of the model of König et al. (2017) is the fact that voters with different incomes may support the same redistributive policy (i.e., the public provision of the good). This finding is consistent with empirical evidence and survey data. However, the same data highlight the simultaneous existence of another typical pattern: people with the same level of income often support different redistributive policies. A paper that accounts for both patterns, and

\footnotetext{
5 Kim (2018) instead rationalizes the economic conservatism of the poor in a model in which agents have (ordinal) positional concerns on consumption, they display last-place aversion (i.e., the disutility they experience in moving from position $k$ to position $k+1$ in the ranking is strictly increasing in $k$; see Kuziemko et al. (2014)), and their labor productivity gets slightly perturbed by the introduction of new tax policies.
} 
it is therefore able to simultaneously rationalize both deviations from pure economic voting, is Gallice and Grillo (2018a).

Gallice and Grillo (2018a) introduce a model in which agents are heterogeneous in two dimensions: productivity and social class. Productivity determines an agent's gross income. Social class captures all of the factors that influence an agent's social position after having controlled for the income consequences that these factors generate. Examples of these factors include the agent's educational and cultural level and the social network that he inherits from his family. Gallice and Grillo (2018a) then define social status as a weighted average of the agent's relative standing in the distributions of consumption and social class. The authors adopt a cardinal formulation of status (which in their model is a multidimensional attribute) because individuals get extra utility (disutility) that is proportional to the positive (negative) distance between the agent's attributes and the average values in the population. ${ }^{6}$ Redistribution impacts citizens' well-being not only because it reallocates resources from the rich to the poor but also because it endogenously affects the weights that define the importance of consumption and social class in determining agents' overall social status. In particular, a high level of redistribution makes consumption less salient (and therefore simultaneously increases the weight attached to social class) since differences across agents in that dimension will be less pronounced. Gallice and Grillo (2018a) characterize the coalitions of heterogeneous voters that support any specific tax rate and show that, as status concerns become more relevant, individual preferences for redistribution become more polarized.

Positional concerns can also drive an agent's process of social identification within a certain social group. This effect can in turn influence the agent's redistributive preferences and cause the individual to deviate from pure economic voting. This path is the one explored by Shayo (2009) with his model of social identity. Contrary to the studies that I reviewed so far (but in line with insights from social psychology), Shayo (2009) defines social status at the group level rather than at the individual level. He uses a cardinal formulation: group status is given by a linear function of the distance between some measure of the group's achievement in the relevant dimension of social comparison (e.g., wealth, income or educational achievements) and the analogous achievement of some reference group. Shayo (2009) then defines the notion of social identification. An individual identifies with a certain social group if he cares about the status of that group (perhaps up to the point of sacrificing material payoff to enhance it) and wishes to conform to that group's standards. ${ }^{7}$ Agents tend to identify with the groups they are more similar to and aspire to join high-status groups rather than low-status groups. When social identification is at work, an agent may support the redistributive policy that is more favorable to the group as a whole, even if this policy is not necessarily the one that benefits him the most as an individual. ${ }^{8}$ Shayo (2009) considers two

6 Gallice and Grillo (2018b) adopt a similar cardinal notion in the context of educational choices. In particular, they study how status concerns influence individual educational choices and inequality when the status-bearing object is the agents' educational level, their perceived ability, or their income. Gallice (2009) also investigates the consequences of relative comparisons in terms of level of schooling on educational dynamics.

7 The sense of belonging to a group with a certain status, together with the related notion of social esteem, is thus what matters to the individual, on top of his material payoff.

8 Klor and Shayo (2010) provide experimental evidence on this tendency. Luttmer (2001) uses instead survey data to show that group loyalty, and in particular racial group loyalty, matters in determining individuals' support for welfare spending. 
social groups with which an agent can identify: his own social class or the nation as a whole. He shows that poor individuals are more likely to identify with the nation and that this nationalistic attitude decreases their support for redistributive policies. This pattern therefore also rationalizes the puzzling observation that, in general, there is a negative relation between the relevance of national identification and the level of redistribution.

To sum up, the papers that I surveyed in this section testify the relevance of social status concerns in influencing individuals' preferences for redistribution. In particular, status-seeking behavior can help rationalize the systematic deviations from pure economic voting that international surveys routinely display. Some of the people whose gross income is below the mean may oppose high taxation because more redistribution could negatively impact on their status (say by lowering the level of their social interactions, by decreasing the expected quality of their matches, or by increasing the salience of some dimensions over which they are particularly weak). Similarly, some of the people whose gross income is above the mean may support high levels of redistribution as this could benefit their social standing (say by relaxing the pressures to engage in costly sorting, or by preserving the exclusivity of their consumption choices). As the intertwinement of different notions of social status, different status-bearing objects and different reference groups has only begun to be unraveled, theoretical and empirical research in this area is likely to remain lively and fruitful. ${ }^{9}$

\section{Social Status and Optimal Direct Taxation}

As noted in the Introduction, studies of how social status concerns may impact the design of fiscal policies typically adopt more of a normative approach because they investigate how optimal direct taxation should be adjusted to account for agents' concerns for their relative standing. For instance, status-seeking considerations may lead individuals to overindulge in the status-bearing activity (e.g., consume too much of a positional good) and therefore move away from the first-best solution (e.g., by inflating the labor supply so as to increase their consumption possibilities). Moreover, status competition creates negative externalities on others; agents can improve their relative standing only by climbing the social ladder, thereby automatically worsening the position of someone else. ${ }^{10}$ Taxation can mitigate, or sometimes fully eliminate, these distortions. A properly designed income tax can contrast agents' desire to increase their labor supply, perhaps discriminating across different types of individuals who face different incentives to engage in social competition. Similarly, a Pigouvian tax on positional goods can force agents to internalize the social costs that they generate by overspending in conspicuous consumption and accordingly correct the negative externalities that social competition brings.

\footnotetext{
9 Ongoing studies on the topic also include Windsteiger (2017), who rationalizes the observation that redistributive policies appear to get lower support as income inequality increases in a model in which people are segregated according to income and misperceive the shape of the income distribution, and Antinyan et al. (2018), who use an agent-based model to study the welfare implications of status competition and redistributive policies in an evolving social network. ${ }^{10}$ The kind of social competition that I consider in this section involves all individuals, even those at the top of the distribution of the status-bearing object. Thus, agents do not have an emulative behavior (sometimes labelled by the 'Keeping up with the Joneses' idiom) but rather a competitive one ('Staying ahead of the Smiths').
} 
The welfare-improving role that taxation can play when agents care about their relative position in the society has long been recognized in the literature. Older studies that address this issue are, among others: Duesenberry (1949), Boskin and Sheshinski (1978), Oswald (1983), Frank (1985), Ireland (1994), Persson (1995), Corneo and Jeanne (1997a), and Ireland (1998). In what follows, I focus on more recent contributions. I concentrate on papers that model and investigate the issue in a game theoretic setting as a simultaneous and one-shot interaction among individuals. ${ }^{11}$ However, even in this restricted temporal and methodological domain, relevant contributions remain numerous and I will therefore only consider some of them.

In discussing this selected group of papers, I attempt to highlight how these studies address the primary research questions underlying the literature on the topic. These questions can be summarized as follows: how does the presence of status concerns modify optimal direct taxation with respect to the conventional case in which these concerns are absent? Does the fact that agents care about their relative standing call for a more or less pronounced progressivity of the tax system with respect to the "standard" level of progressivity that simply stems out from the decreasing marginal utility of income? Finally, which are the consequences that status concerns brings about in terms of the shape (i.e., the concavity or convexity) of the optimal tax schedule? As we will see, the answer to the first question is rather uncontroversial as it appears to be robust to different matching protocols and different specifications of social status. The existence of status concerns generally calls for an increase in taxation for all types of agents. This increase is justified by a Pigouvian argument. It serves to realign the private and social costs that stem from social competition and thereby eliminate the negative externalities that status concerns generate. ${ }^{12}$ The answers to the second and third questions (effects on the progressivity and the shape of the optimal tax schedule) are less univocal because they are sensitive to the formulation of social status that one adopts.

The first paper that I discuss is Ireland (2001). This study investigates the issue of optimal income tax in a model that features a social status signaling mechanism. In the model, individuals choose their labor supply and signal their status via wasteful consumption expenditure. The government observes the income profile and chooses the income tax schedule that maximizes social welfare (a weighted average of individual utilities, where the weights are non-increasing in agents' types). Social concerns are captured by postulating that agents maximize a weighted average of their actual utility and their utility as perceived by others, where the weight of the second component is weakly increasing in agents' type (i.e., higher types may be more concerned about status than lower types). Assuming quasi-linear preferences in consumption and focusing on the least-inefficient fully separating equilibrium, Ireland (2001) shows that, compared with the conventional case in which status concerns play no role, the optimal tax policy is more progressive

\footnotetext{
${ }^{11}$ Therefore, I exclude papers that study the intertemporal profile of optimal taxation in the presence of status concerns and feature overlapping generations of individuals (Abel, 2005; Aronsson and Johansson-Stenman, 2010; Wendner, 2010).

${ }^{12}$ Under some circumstances, the quest for status may actually incentivize activities that generate positive externalities. Social competition can then counteract pre-existing distortions and lead to welfare improvements. See Corneo and Jeanne (1997b) for an example about capital accumulation in an endogenous growth framework.
} 
because it features steeper tax functions for all agents. ${ }^{13}$ The tax system thus leads to more redistribution. However, the analysis also shows that in general marginal tax rates do not have to increase faster with agents' types, which can actually only occur when the rich are more concerned with status than the poor. Therefore, the optimal tax schedule is not necessarily more convex. As Ireland (2001) puts it: "Status seeking justifies income taxation and higher marginal tax rate, but not an increasing marginal tax rate".

Corneo (2002) investigates the efficiency of progressive taxation when agents care about relative income. This study illustrates the beneficial effects that progressive taxation may have as a way to contrast the negative externalities that status concerns generate. The rat race triggered by social competition leads to upward distortions in individuals' labor supply because agents want higher incomes to finance higher levels of consumption. Progressive taxation can restore efficiency because those who strive the most to improve their status are high-income individuals and therefore high marginal tax rates are necessary to prevent them from doing so. Corneo (2002) considers a model in which agents are heterogeneous in terms of their time endowments, and therefore earning potentials. He defines status as an ordinal concept: it is given by the agent's rank in the post-tax income (or equivalently consumption) distribution and can accordingly be measured by the cumulative distribution function of income. This formulation leads to interesting results. It implies, for instance, that the incentives to engage in status-seeking behaviors are stronger in more equal societies because an individual can move up more in the social ranking when income differences are limited. That is why the benefits of progressive taxation are larger when the distribution of income in the society is more homogeneous; this situation is one in which individual incentives to engage in social competition, and thereby upwardly distort their labor supply, are stronger. Indeed, Corneo (2002) shows that, whenever income inequality is below a critical threshold, a progressive income tax can even yield Pareto improvements: the poor enjoy a higher level of redistribution while the rich save on the costs of the status race. In general, the author shows that a properly structured progressive taxation can restore agents' undistorted first-best labor supply. The amount of progressivity (i.e., the steepness of the optimal tax schedule) that is necessary to achieve this result decreases with inequality. The model accordingly provides an explanation as to why income taxation appears to be more redistributive in countries that are relatively homogeneous in terms of pre-tax income.

In an influential paper, Hopkins and Kornienko (2004) delve into a similar topic. These authors consider a simultaneous move game with incomplete information in which agents must decide how much of their (unobservable) income to devote to the conspicuous consumption of a positional good. Agents care about their absolute level of consumption as well as about their status, which is determined by their ranking in the distribution of consumption of the positional good (therefore status has an ordinal formulation). As a result, agents have to anticipate the amount that others will consume and best respond to this guess. Hopkins and Kornienko (2004) show that in the symmetric equilibrium of the game, the distribution of consumption resembles the distribution of

\footnotetext{
${ }^{13}$ On a related note, see also Aronsson and Johansson-Stenman (2008). These authors show that concerns about relative consumption lead to (substantially higher) marginal tax rates with respect to the conventional case in which these concerns are absent. Aronsson and Johansson-Stenman (2008) investigate the consequences of relative concerns not only in terms of optimal income taxation but also in terms of public good provision (about this latter point see also $\mathrm{Ng}$ (1987) and Wendner and Goulder (2008)).
} 
income because each agent has the same rank under both distributions. People over-spend in the positional good but in equilibrium individual investments cancel out: agents are not able to change their initial position and basically "run to keep in the same place". In terms of policy implications, the analysis reveals that taxing conspicuous consumption can improve social welfare because it disincentives the race for status. In particular, Hopkins and Kornienko (2004) show that as income becomes more homogeneous the marginal tax rate on middle incomes should rise. Like Corneo (2002), the intuition is that a low level of income inequality fosters social competition because agents that are in the middle of the distribution can more easily outperform a large numbers of their peers (see also Hopkins and Kornienko (2009)). However, the tax rate on high incomes (and under certain conditions also the rate on low incomes) should fall because at the extremes of the distribution the incentives to improve one's own rank are lower. The optimal tax schedule therefore discriminates among agents by targeting the different level of social competition they face rather than their expenditure on conspicuous consumption (which is increasing with the agents' income). Hence, the analysis by Hopkins and Kornienko (2004) challenges the idea that progressive taxation is necessarily the optimal policy when people display status concerns.

Bilancini and Boncinelli (2012) elaborate on these insights and convincingly demonstrate an important result: the equilibrium outcomes of models that feature status concerns, and therefore also their policy and welfare implications, strongly depend on the shape and the properties of the status function. In their model, "rich" and "poor" individuals have a non-observable endowment of resources (the status-bearing object). The authors deliberately avoid defining these resources precisely because they can take on different meanings (e.g., income, consumption, wealth) depending on the context. Agents can signal their status by spending on a conspicuous good. However, these expenditures are socially wasteful. Bilancini and Boncinelli (2012) consider two different functional forms for status. The first one is an ordinal notion that only depends on the agent's rank in the distribution. The second one is a cardinal notion that also takes into account the distance between an agent and the other agents. Within such a framework, Bilancini and Boncinelli (2012) analyze the effects of redistributive policies in favor of the poor. Consistent with the findings of Hopkins and Kornienko (2004), they show that with ordinal status, redistribution boosts social waste because it shrinks the consumption distribution and thereby fosters social competition. However, if status is cardinal an additional effect kicks in because a more compressed distribution lowers the social prestige (respectively, social stigma) that people perceived to be rich (respectively, poor) enjoy. This second effect reduces the incentives to signaling and, if it overcomes the first effect, may actually lead to a reduction in social waste. When this is the case and the reduction in social waste is sizable, more redistribution from the rich to the poor (i.e., a more compressed income distribution) may even lead to a Pareto improvement because the rich can get compensated for both the loss of resources and the loss of status that they suffer. ${ }^{14}$ A part from these specific findings, the important message that Bilancini and Boncinelli (2012) convey is

\footnotetext{
${ }^{14}$ Bilancini and Boncinelli (2018) deepen the analysis by focusing on the case in which labor income is the statusbearing object (and still provides the agent the purchasing power to buy the conspicuous good). They show that in such a framework the (positive or negative) effects of income taxes in reducing social waste depend in an even more complex way on the combination between the distribution of pre-tax wages and the social norm about status (ordinal status vs. cardinal status).
} 
that, even if one is convinced that in a certain context status considerations are at work, the choice of which notion / functional form of status to adopt is not inconsequential. ${ }^{15}$

Aronsson and Johansson-Stenman (2013) enlarge the scope of the analysis by studying the issue of optimal direct taxation in a context in which both consumption and leisure are conspicuous goods that convey status (though consumption is possibly more salient). The authors introduce a model in which individuals must decide their labor supply while caring about their absolute and relative levels of consumption and leisure. Status is a cardinal notion and is measured by the distance between the agent's consumption and time spent on leisure and the average values in the population. Aronsson and Johansson-Stenman (2013) show that in such a context a progressive tax schedule on income is the optimal policy. ${ }^{16}$ As in other models, a higher level of taxation with respect to a setting in which social status plays no role serves the purposes of internalizing the externalities that concerns about relative consumption generate. Progressivity then stems from the positional nature of leisure: as agents increase their labor supply to boost their consumption (thereby generating a negative externality on others in the consumption dimension), they necessarily have to reduce their time spent on leisure (thereby generating a positive externality in the leisure dimension, which accordingly offsets, but only partially, the negative externality in the consumption dimension). However, to sustain any given level of consumption, low-ability (i.e., low-income) individuals must decrease their amount of leisure by more than high-ability agents. The optimal marginal tax rate must therefore be higher for high-ability individuals to account for the fact that the positive externalities that these individuals generate by decreasing their amount of leisure is lower.

Finally, Kanbur and Tuomala (2013) focus on how the relevance of relative concerns impacts optimal direct taxation. They study a model in which consumption is the object of social comparisons, individual status is measured in a cardinal way because it depends (positively or negatively) on the (positive or negative) distance from the population average, and the government taxes income with the goal of maximizing a utilitarian social welfare function. ${ }^{17}$ Consistent with Ireland (2001) and Corneo (2002), the authors' results confirm the general finding that higher marginal tax rates improve efficiency when people have status concerns. In particular, Kanbur and Tuomala (2013) show that stronger concerns for one's own relative position increase the progressivity and the convexity of the optimal tax schedule. Interestingly, Kanbur and Tuomala (2013) also study how the level of inequality in the society affects the impact of the salience of relative concerns on optimal taxation. Using some specific functional forms and numerical simulations, Kanbur and Tuomala (2013) show that higher inequality reduces the positive impact of the degree of relative concerns both on the level and on the steepness of the optimal marginal tax rate schedule. However, and as the authors first advocate, more research is needed on this issue to better understand the generality of this relation and disentangle the various forces at play in it.

\footnotetext{
${ }^{15}$ I again refer the reader to Bilancini and Boncinelli $(2008,2014)$ for some clear examples about how different formulations of ordinal and cardinal status can substantially impact the results of the analysis.

${ }^{16}$ Mujcic and Frijters (2015) derive similar implications in a model in which consumption and health are conspicuous goods. These authors use survey data from Australia to show that health is indeed a status-bearing object.

${ }^{17}$ See Aronsson and Johansson-Stenman (2018) for an analysis of the case in which the government instead adopts a paternalistic approach and thereby does not internalize the welfare effects of relative consumption in the social objective function.
} 
To summarize, all papers in this area of research highlight the distorsive effects that statusseeking behavior may have both at the individual and at the aggregate level. Agents tend to spend too much in positional goods and may thus push their labor supply above the first-best solution. The externalities that stem from the rat-race effects that are inherent to social competition further exacerbate the problem. All papers also recognize the role of taxation to mitigate these effects. The optimal tax policy depends however on a number of context-specific characteristics, among which the level of pre-tax inequality and the relevant notion of social status prominently stand out.

\section{Conclusions}

I have reviewed recent studies investigating how concerns about one's own relative standing in the society affect individual attitudes towards redistribution and the design of optimal tax policies. In both contexts, status considerations lead agents to behave differently with respect to the optimal behavior they should adopt if only monetary payoffs were relevant. Models that explicitly acknowledge the importance of status concerns in driving individual decisions can thus provide a better description of agents' actual behavior. In particular, these models can rationalize patterns of behavior that would otherwise appear to be suboptimal. The papers that I reviewed demonstrate, for instance, that social competition can explain why a non-negligible fraction of the population supports redistributive policies that harm them from a purely monetary point of view. Similarly, they show that status-seeking behavior may influence agents' labor supply, bias their consumption habits, and accordingly call for specific tax interventions on the side of the government to counterbalance these distortions and improve efficiency. Current research about the role that status concerns may play in these contexts is lively and will certainly lead to a wider and sharper array of sensible policy implications.

\section{References}

Abel, A. B. (2005). Optimal taxation when consumers have endogenous benchmark levels of consumption. The Review of Economic Studies, 72(1): 21-42. URL http://www.jstor.org/stable/ 3700682 .

Alesina, A., and Angeletos, G.-M. (2005). Fairness and redistribution. American Economic Review, 95(4): 960-980. URL http://www.aeaweb.org/articles?id=10.1257/0002828054825655.

Alesina, A., and Ferrara, E. L. (2005). Preferences for redistribution in the land of opportunities. Journal of Public Economics, 89(5): 897-931. URL http://www.sciencedirect.com/science/ article/pii/S0047272704000866.

Alesina, A., and Giuliano, P. (2011). Preferences for redistribution. In J. Benhabib, A. Bisin, and M. O. Jackson (Eds.), Handbook of Social Economics, volume 1, pages 93-131. North-Holland. URL http://www.sciencedirect.com/science/article/pii/B9780444531872000048.

Antinyan, A., Horvath, G., and Jia, M. (2018). Social status competition and the impact of income inequality in evolving social networks: An agent-based model. Mimeo. 
Aronsson, T., and Johansson-Stenman, O. (2008). When the Joneses' consumption hurts: Optimal public good provision and nonlinear income taxation. Journal of Public Economics, 92(5): 986-997. URL http://www.sciencedirect.com/science/article/pii/S0047272707002083.

Aronsson, T., and Johansson-Stenman, O. (2010). Positional concerns in an OLG model: Optimal labor and capital income taxation. International Economic Review, 51(4): 1071-1095. URL https://onlinelibrary.wiley.com/doi/abs/10.1111/j.1468-2354.2010.00611.x.

Aronsson, T., and Johansson-Stenman, O. (2013). Conspicuous leisure: Optimal income taxation when both relative consumption and relative leisure matter. The Scandinavian Journal of Economics, 115(1): 155-175. URL https://onlinelibrary.wiley.com/doi/abs/10.1111/j.1467-9442. 2012.01738.x.

Aronsson, T., and Johansson-Stenman, O. (2018). Paternalism against Veblen: Optimal taxation and non-respected preferences for social comparisons. American Economic Journal: Economic Policy, 10(1): 39-76. URL http://www.aeaweb.org/articles?id=10.1257/pol.20150369.

Bénabou, R., and Ok, E. A. (2001). Social mobility and the demand for redistribution: The poum hypothesis. The Quarterly Journal of Economics, 116(2): 447-487. URL http://dx.doi.org/10. 1162/00335530151144078.

Bénabou, R., and Tirole, J. (2006). Belief in a just world and redistributive politics. The Quarterly Journal of Economics, 121(2): 699-746. URL http://dx.doi.org/10.1162/qjec.2006.121.2.699.

Bilancini, E., and Boncinelli, L. (2008). Ordinal vs cardinal status: Two examples. Economics Letters, 101(1): 17-19. URL http://www.sciencedirect.com/science/article/pii/S0165176508001079.

Bilancini, E., and Boncinelli, L. (2012). Redistribution and the notion of social status. Journal of Public Economics, 96(9): 651-657. URL http://www.sciencedirect.com/science/article/pii/ S0047272712000461.

Bilancini, E., and Boncinelli, L. (2014). Instrumental cardinal concerns for social status in twosided matching with non-transferable utility. European Economic Review, 67: 174-189. URL http://www.sciencedirect.com/science/article/pii/S0014292114000269.

Bilancini, E., and Boncinelli, L. (2018). Wage inequality, labor income taxes, and the notion of social statu. Economics Discussion Papers 2018-41, Kiel Institute for the World Economy. URL http://www.economics-ejournal.org/economics/discussionpapers/2018-41.

Boskin, M. J., and Sheshinski, E. (1978). Optimal redistributive taxation when individual welfare depends upon relative income. The Quarterly Journal of Economics, 92(4): 589-601. URL http://dx.doi.org/10.2307/1883177.

Chao, A., and Schor, J. B. (1998). Empirical tests of status consumption: Evidence from women's cosmetics. Journal of Economic Psychology, 19(1): 107-131. URL http://www.sciencedirect. com/science/article/pii/S016748709700038X. 
Cole, H. L., Mailath, G. J., and Postlewaite, A. (1992). Social norms, savings behavior, and growth. Journal of Political Economy, 100(6): 1092-1125. URL https://doi.org/10.1086/261855.

Corneo, G. (2002). The efficient side of progressive income taxation. European Economic Review, 46(7): 1359-1368. URL https://ideas.repec.org/a/eee/eecrev/v46y2002i7p1359-1368.html.

Corneo, G., and Grüner, H. P. (2000). Social limits to redistribution. The American Economic Review, 90(5): 1491-1507. URL http://www.jstor.org/stable/2677862.

Corneo, G., and Grüner, H. P. (2002). Individual preferences for political redistribution. Journal of Public Economics, 83(1): 83-107. URL http://www.sciencedirect.com/science/article/pii/ S0047272700001729.

Corneo, G., and Jeanne, O. (1997a). Conspicuous consumption, snobbism and conformism. Journal of Public Economics, 66(1): 55-71. URL http://www.sciencedirect.com/science/article/ pii/S0047272797000169.

Corneo, G., and Jeanne, O. (1997b). On relative wealth effects and the optimality of growth. Economics Letters, 54(1): 87-92. URL http://www.sciencedirect.com/science/article/pii/ S0165176596009408.

Duesenberry, J. (1949). Income, saving, and the theory of consumer behavior. Harvard economic studies. Harvard University Press. URL https://books.google.it/books?id=SyheAAAAIAAJ.

Ferrari, L. (2018). Social limits to redistribution and conspicuous norms. Economics Discussion Papers 2018-30, Kiel Institute for the World Economy. URL http://www.economics-ejournal. org/economics/discussionpapers/2018-30.

Fong, C. (2001). Social preferences, self-interest, and the demand for redistribution. Journal of Public Economics, 82(2): 225-246. URL http://www.sciencedirect.com/science/article/pii/ S0047272700001419.

Frank, R. H. (1985). The demand for unobservable and other nonpositional goods. The American Economic Review, 75(1): 101-116. URL http://www.jstor.org/stable/1812706.

Gallice, A. (2009). Education, dynamic signalling, and social distance. Oxford Economic Papers, 61(2): 304-326. URL http://www.jstor.org/stable/20529419.

Gallice, A., and Grillo, E. (2018a). Economic and social-class voting in a model of redistribution with social concerns. Carlo Alberto Notebooks 448, Collegio Carlo Alberto.

Gallice, A., and Grillo, E. (2018b). A model of educational investment, social concerns, and inequality. The Scandinavian Journal of Economics, forthcoming. URL https://onlinelibrary. wiley.com/doi/abs/10.1111/sjoe.12299.

Giuliano, P., and Spilimbergo, A. (2014). Growing up in a recession. The Review of Economic Studies, 81(2): 787-817. URL http://dx.doi.org/10.1093/restud/rdt040. 
Heffetz, O., and Frank, R. H. (2011). Preferences for status: Evidence and economic implications. In J. Benhabib, A. Bisin, and M. O. Jackson (Eds.), Handbook of Social Economics, volume 1, pages 69-91. North-Holland. URL http://www.sciencedirect.com/science/article/pii/ B9780444531872000036.

Hopkins, E., and Kornienko, T. (2004). Running to keep in the same place: Consumer choice as a game of status. American Economic Review, 94(4): 1085-1107. URL http://www.aeaweb.org/ articles?id=10.1257/0002828042002705.

Hopkins, E., and Kornienko, T. (2009). Status, affluence, and inequality: Rank-based comparisons in games of status. Games and Economic Behavior, 67(2): 552-568. URL https://ideas.repec. org/a/eee/gamebe/v67y2009i2p552-568.html.

Ireland, N. (2001). Optimal income tax in the presence of status effects. Journal of Public Economics, 81(2): 193-212. URL http://www.sciencedirect.com/science/article/pii/ S0047272700001080.

Ireland, N. J. (1994). On limiting the market for status signals. Journal of Public Economics, 53(1): 91-110. URL http://www.sciencedirect.com/science/article/pii/0047272794900159.

Ireland, N. J. (1998). Status-seeking, income taxation and efficiency. Journal of Public Economics, 70(1): 99-113. URL http://www.sciencedirect.com/science/article/pii/S0047272798000620.

Kanbur, R., and Tuomala, M. (2013). Relativity, inequality, and optimal nonlinear income taxation. International Economic Review, 54(4): 1199-1217. URL https://onlinelibrary.wiley.com/doi/ abs/10.1111/iere.12033.

Kim, D. G. (2018). Positional concern and low demand for redistribution of the poor. European Journal of Political Economy, forthcoming. URL http://www.sciencedirect.com/science/article/ pii/S0176268018300880.

Klor, E. F., and Shayo, M. (2010). Social identity and preferences over redistribution. Journal of Public Economics, 94(3): 269-278. URL http://www.sciencedirect.com/science/article/pii/ S0047272709001649.

König, T., Lausen, T., and Wagener, A. (2017). Image concerns and the political economy of publicly provided private goods. CESifo Working Paper Series 6304, CESifo Group Munich. URL https://ideas.repec.org/p/ces/ceswps/_6304.html.

Kuziemko, I., Buell, R. W., Reich, T., and Norton, M. I. (2014). Last-place aversion: Evidence and redistributive implications. The Quarterly Journal of Economics, 129(1): 105-149. URL http://dx.doi.org/10.1093/qje/qjt035.

Levy, G., and Razin, R. (2015). Preferences over equality in the presence of costly income sorting. American Economic Journal: Microeconomics, 7(2): 308-337. URL http://www.aeaweb.org/ articles?id=10.1257/mic.20130031. 
Luttmer, E. F. P. (2001). Group loyalty and the taste for redistribution. Journal of Political Economy, 109(3): 500-528. URL https://doi.org/10.1086/321019.

Luttmer, E. F. P. (2005). Neighbors as negatives: Relative earnings and well-being. The Quarterly Journal of Economics, 120(3): 963-1002. URL http://dx.doi.org/10.1093/qje/120.3.963.

Luttmer, E. F. P., and Singhal, M. (2011). Culture, context, and the taste for redistribution. American Economic Journal: Economic Policy, 3(1): 157-179. URL http://www.aeaweb.org/ articles?id=10.1257/pol.3.1.157.

Meltzer, A. H., and Richard, S. F. (1981). A rational theory of the size of government. Journal of Political Economy, 89(5): 914-927. URL http://www.jstor.org/stable/1830813.

Mujcic, R., and Frijters, P. (2015). Conspicuous consumption, conspicuous health, and optimal taxation. Journal of Economic Behavior \& Organization, 111(C): 59-70. URL https://EconPapers.repec.org/RePEc:eee:jeborg:v:111:y:2015:i:c:p:59-70.

Ng, Y.-K. (1987). Relative-income effects and the appropriate level of public expenditure. Oxford Economic Papers, 39(2): 293-300. URL http://www.jstor.org/stable/2663267.

Oswald, A. J. (1983). Altruism, jealousy and the theory of optimal non-linear taxation. Journal of Public Economics, 20(1): 77-87. URL http://www.sciencedirect.com/science/article/pii/ $004727278390021 X$.

Persson, M. (1995). Why are taxes so high in egalitarian societies? The Scandinavian Journal of Economics, 97(4): 569-580. URL http://www.jstor.org/stable/3440543.

Piketty, T. (1995). Social mobility and redistributive politics. The Quarterly Journal of Economics, 110(3): 551-584. URL http://www.jstor.org/stable/2946692.

Postlewaite, A. (1998). The social basis of interdependent preferences. European Economic Review, 42(3-5): 779-800. URL https://EconPapers.repec.org/RePEc:eee:eecrev:v:42:y:1998:i: 3-5:p:779-800.

Rege, M. (2008). Why do people care about social status? Journal of Economic Behavior \& Organization, 66(2): 233-242. URL https://ideas.repec.org/a/eee/jeborg/v66y2008i2p233-242. html.

Roberts, K. W. (1977). Voting over income tax schedules. Journal of Public Economics, 8(3): 329-340. URL http://www.sciencedirect.com/science/article/pii/0047272777900056.

Romer, T. (1975). Individual welfare, majority voting, and the properties of a linear income tax. Journal of Public Economics, 4(2): 163-185. URL http://www.sciencedirect.com/science/article/ pii/004727277590016X.

Shayo, M. (2009). A model of social identity with an application to political economy: Nation, class, and redistribution. American Political Science Review, 103(2): 147-174. 
Solnick, S., and Hemenway, D. (1998). Is more always better?: A survey on positional concerns. Journal of Economic Behavior \& Organization, 37(3): 373-383. URL https://EconPapers.repec. org/RePEc:eee:jeborg:v:37:y:1998:i:3:p:373-383.

Solnick, S. J., and Hemenway, D. (2005). Are positional concerns stronger in some domains than in others? The American Economic Review, 95(2): 147-151. URL http://www.jstor.org/stable/ 4132807.

Truyts, T. (2010). Social status in economic theory. Journal of Economic Surveys, 24(1): 137-169. URL https://onlinelibrary.wiley.com/doi/abs/10.1111/j.1467-6419.2009.00579.x.

Wendner, R. (2010). Conspicuous consumption and generation replacement in a model of perpetual youth. Journal of Public Economics, 94(11): 1093-1107. URL http://www.sciencedirect.com/ science/article/pii/S0047272710001118.

Wendner, R., and Goulder, L. H. (2008). Status effects, public goods provision, and excess burden. Journal of Public Economics, 92(10): 1968-1985. URL http://www.sciencedirect.com/science/ article/pii/S004727270800073X.

Windsteiger, L. (2017). The redistributive consequences of segregation. Working Paper 2017-12, Max Planck Institute for Tax Law and Public Finance. URL http://www.econ.jku.at/members/ Department/files/ResearchSeminar/SS18/Windsteiger.pdf. 


\section{Economics}

Please note:

You are most sincerely encouraged to participate in the open assessment of this article. You can do so by either recommending the article or by posting your comments.

\section{Please go to:}

http://dx.doi.org/10.5018/economics-ejournal.ja.2018-55

The Editor 